\begin{tabular}{|c|c|c|}
\hline $\begin{array}{l}\text { PKS } \\
\text { PUBLCC } \\
\text { KNOOLEDGE } \\
\text { PROJECT }\end{array}$ & $\begin{array}{c}\text { Revista de GEOGRAFIA } \\
\text { (RECIFE) } \\
\text { http://www.revista.ufpe.br/revistageografia }\end{array}$ & $\begin{array}{l}\text { OJS } \\
\text { OPEN } \\
\text { JOUNAL } \\
\text { SYSTEMS }\end{array}$ \\
\hline
\end{tabular}

\title{
"PELAS FRESTAS E BECOS DO PATRIMÔNIO": O LUGAR DO (IN) VISÍVEL NO CENTRO HISTÓRICO PROTEGIDO DO RECIFE
}

\author{
Priscila Batista Vasconcelos ${ }^{1}$, Caio Augusto Amorim Maciel ${ }^{2}$, Norma Lacerda $^{3}$ \\ 1 Pós-doutoranda do Programa de Pós-graduação em Desenvolvimento Urbano da UFPE, \\ priscilabv1908@yahoo.com.br \\ ${ }^{2}$ Professor do Programa de Pós-graduação em Geografia da UFPE, caio.maciel@ufpe.br \\ 3 Professora Titular do Programa de Pós-graduação em Desenvolvimento Urbano da UFPE, \\ norma_lac@yahoo.com.br
}

Artigo recebido em 12/09/2017 e aceito em 02/10/2017

\begin{abstract}
RESUMO
O artigo tem por objetivo a reflexão sobre os becos como o lugar do (in) visível na dinâmica urbana de centros históricos protegidos. A questão que move a pesquisa se expressa da seguinte maneira: por que, apesar da importância na história e cultura do bairro de São José, as vielas não fazem parte da iconografia simbólica do Recife patrimonializado? Partimos da hipótese de que, no atual "regime escópico" que orienta as visualidades e as imagens icônicas do perímetro tombado do bairro de São José, os becos têm pouco ou nenhum lugar de realce, em função de uma herança pejorativa do olhar.
\end{abstract}

Palavras-chave: Patrimônio, Centro Histórico, becos

\section{"THROUGH HERITAGE GAPS AND ALLEYS": THE PLACE OF (IN) VISIBLE IN THE PROTECTED HISTORICAL CENTER OF RECIFE CITY}

\begin{abstract}
The article aims to reflect on the alleys as places of (in)visible in the urban dynamics of protected historical centers. The question that moves the research is expressed as follows: why, despite their importance in the history and urban culture of the São José district, are the lanes not part of the symbolic iconography of the protected areas of Recife? We hypothesize that in the current "scopic regime" that guides the visual and iconic images of the perimeter of São José neighborhood, the alleys have little or no place of emphasis, due to a pejorative heritage of the gaze.
\end{abstract}

Key-words: Heritage; Historical Centre; Alleys 


\section{CONSIDERAÇÕES INICIAIS}

Os espaços patrimonializados das cidades remetem, amiúde, à imagens panorâmicas dos seus lugares mais icônicos, associadas à fotografias postais de construções e monumentos com amplo reconhecimento geossimbólico. Inseridos em tal dinâmica metonímica (MACIEL, 2012), trechos recônditos dos perímetros tombados podem sofrer um processo de invisibilização, tal como ocorre com os becos do bairro de São José, no Centro Histórico do Recife-PE.

Apesar de decantados partícipes do "gênio do lugar", congregando tanto funções práticas quanto um imaginário poético e sentimental da urbe (HALLEY, 2012), as vielas dessa área central revelam, contraditoriamente, um precário acervo iconográfico, correlacionado a uma maneira hegemônica e pouco elogiosa de ver os espaços da pobreza, como discutimos em outro momento (VASCONCELOS e MACIEL, 2017).

Consideramos com Qian (2008) que o espírito de um lugar é a soma dos elementos culturais manifestos através dos seus elementos tangíveis e intangíveis, como arquitetura, características naturais, atividades diárias, bem como tradições e costumes de um modo de vida próprio à comunidade que o habita. Daí torna-se importante ressaltar que a tarefa de proteger lugares engloba não só estruturas e morfologias singulares e seu contexto material, mas também a maneira como as pessoas interagem com aquele espaço. Esta premissa pode ser útil para a melhor inserção dos becos de São José na dinâmica do perímetro tombado, uma vez que não se trata aqui de colocar em relevo uma morfologia exuberante ou extensa, mas apontar como a vida nos becos é parte do espírito do bairro.

Mesmo que em diversas partes do mundo os becos reportem-se culturalmente ao pouco visto, ao perigo ou à precariedade de espaços públicos (PESAVENTO, 2001), o caso da iconografia do bairro de São José, pela indigência imagética de suas ruas mais estreitas, justifica uma reflexão sobre o lugar do (in) visível na dinâmica de áreas protegidas. Se o sentido de imperceptibilidade se configura como característica genérica dos becos, a intensa vivência das ruelas do bairro (ver figura 1) pelos que buscam comércio e serviços especializados cotidianamente conforma uma pulsante paisagem não panorâmica, que poderia integrar-se melhor aos preceitos da conservação histórica do perímetro em questão. 
Figura 01: Fluxo intenso diurno nos Becos do bairro de São José, Centro Histórico do Recife.

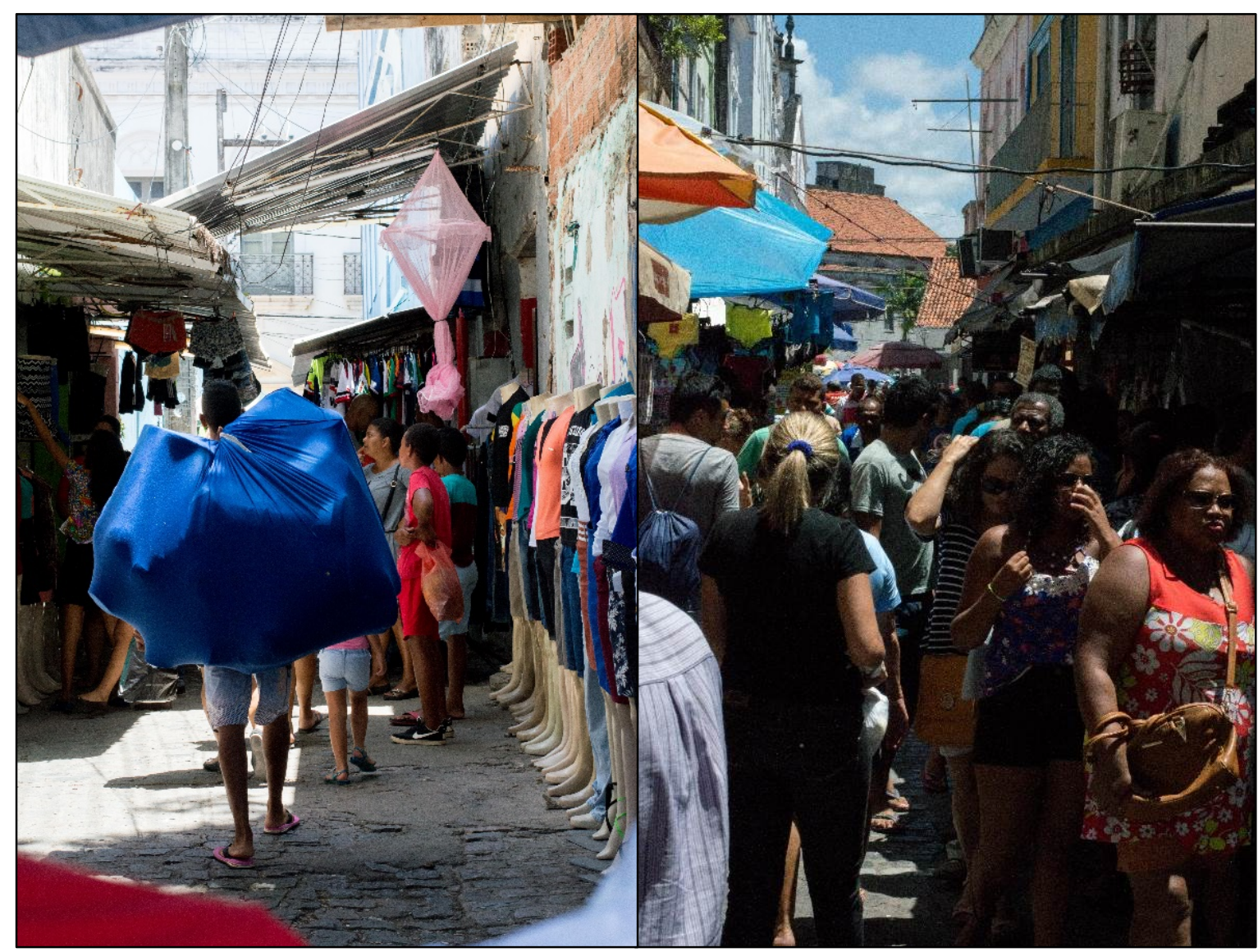

Fonte: Arquivo dos autores, novembro 2017.

De fato, como visto na figura 1, no bairro estudado a maioria dos becos são lócus de intenso fluxo de pessoas, produtos e serviços, inclusive de ambulantes que eventualmente se apropriam de áreas públicas. Carregados de temporalidades passadas, os becos integram uma unidade popularmente referenciada como o centro da cidade ou os arredores do Mercado de São José, onde pulsa o comércio histórico de rua. Mais antigo edifício pré-fabricado em ferro no Brasil (GASPAR, 2017), exportado da Europa para o Recife no final do século XIX (1875), o Mercado marca a dinâmica territorial e turística do bairro, possuindo, ao contrário das pequenas vias, amplo registro iconográfico. Portanto, a questão que move a pesquisa se expressa da seguinte maneira: por que, apesar da importância na história e cultura urbana do bairro de São José, os seus becos não fazem parte da iconografia simbólica do Recife patrimonializado?

Partimos da hipótese de que, no atual "regime escópico" que orienta as visualidades e imagens icônicas do perímetro tombado do bairro de São José, os becos têm pouco ou 
nenhum lugar de realce. Isto se deveria não à desimportância histórica ou hodierna dessas peculiares formas urbanas, mas ao seu renitente aposto de "maus lugares", onde se encontrariam os sujeitos mais despojados e turbulentos da sociedade, para retomar dizeres de Pesavento (2001). Isto é, haveria uma marcada influência de formas pejorativas de ver esses ambientes e seus sujeitos sociais.

Mas, se considerarmos a materialidade intrínseca dessas estreitas ruelas transversais, "o próprio termo 'beco' torna-se condicionante de percepção do espaço assim designado" como afirma Koehler (2015, p.18). Coloca-se aqui o problema de uma perspectiva estigmatizada-estigmatizante, que somente pode ser superada com a desmistificação do caráter precário e marginal desses espaços públicos. Certamente os atuais usuários, consumidores e trabalhadores, têm muito o que dizer sobre as qualidades e vantagens daquelas passagens estreitas, atualizando os fenômenos, eventos e processos que as fizeram sobreviver até os nossos dias - assim como outros modos de olhar (sem condenação ou estigma)

\section{NO AMBIENTE DO PATRIMÔNIO HISTÓRICO}

O tecido urbano do bairro de São José e parte do bairro de Santo Antônio ${ }^{1}$ é formado por um traçado de ruas e becos irregulares, muitos deles desembocando em pátios de igrejas centenárias. Tal trama urbana é tributária do modelo urbanístico lusitano, adotado após a saída dos holandeses (pós 1654). Consoante Amorim \& Loureiro (2006), essa trama acolhe o mais importante conjunto barroco de Pernambuco, que para Amélia Reynaldo (2017, p. 424) o barroco religioso é o grande protagonista erguido desde a segunda metade do século XVII, pois "encerra em si mesmo a representação formal da urbanização e orienta permanentemente a ocupação do espaço". Assim, a paisagem do bairro de São José é formada notadamente pelas igrejas que continuam despontando ao nosso olhar como objetos imponentes no espaço, como podemos observar na figura 02, no primeiro plano, a Igreja de São Pedro dos Clérigos e seu pátio ${ }^{2}$.

\footnotetext{
${ }^{1} \mathrm{Na}$ fronteira entre os bairros de São José e Santo Antônio é de difícil distinção o território que concerne a um e ao outro, pois neste espaço existe um mesmo padrão da trama urbana. Além disso, em termos do imaginário espacial coletivo o bairro de São José se expande adentrando no Bairro de Santo Antônio até os limites das ruas estreitas e intenso comércio. Assim, para efeitos dessa pesquisa o bairro de São José está para além dos limites políticos-administrativos.

${ }^{2}$ Oficialmente faz parte do território político-administrativo do bairro de Santo Antônio.

Vasconcelos, Maciel, Lacerda $2018 \quad$ ISSN 0104-5490 
Figura 02: O protagonismo das Igrejas nos bairros de Santo Antônio e São José.

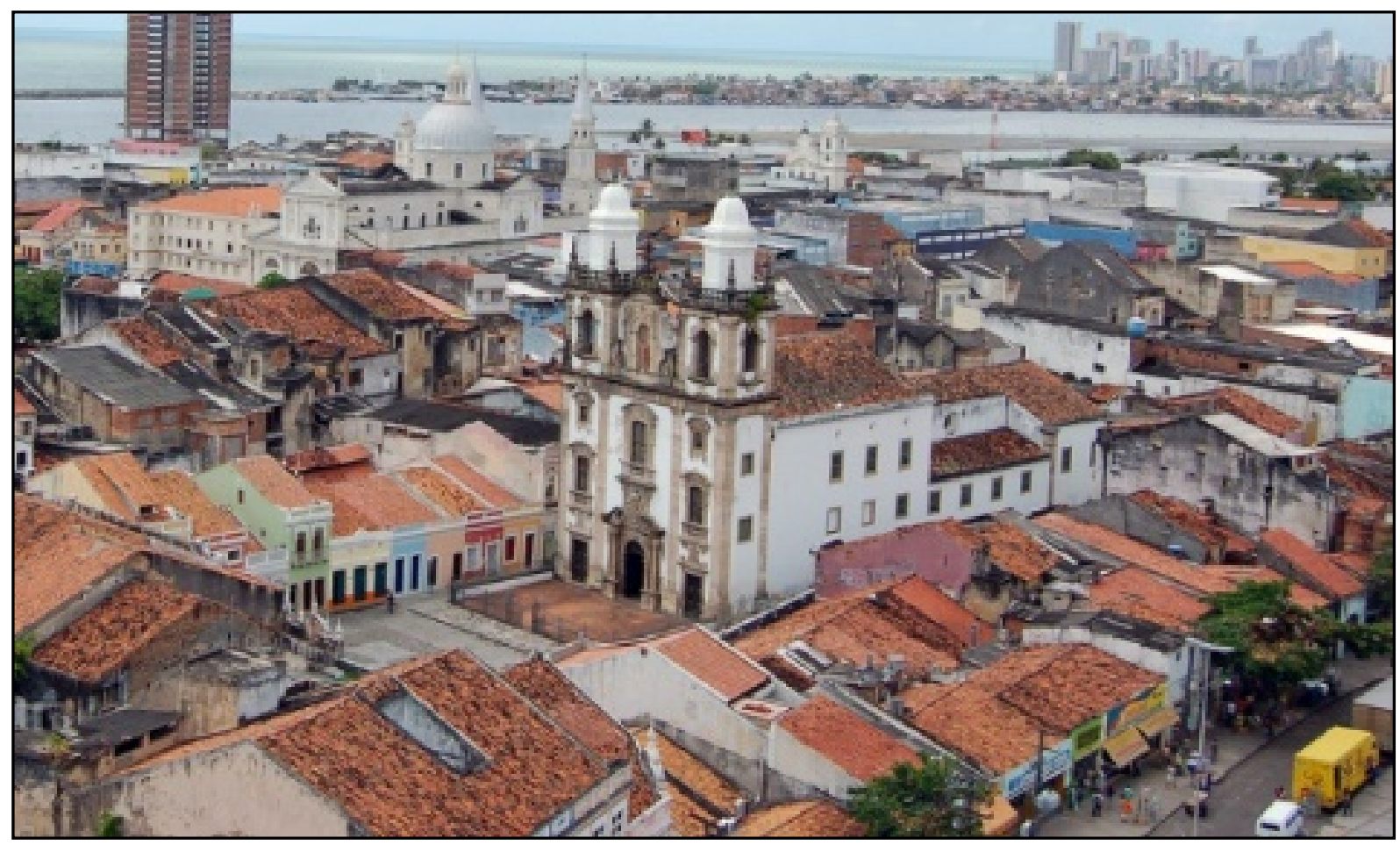

Fonte: site eucurtorecife.com.br/voce-conhece-mesmo-a-cidade-do-recife/, acesso em maio 2017.

Não sem razão sobre esse espaço - com os seus becos, é claro - incide legislação municipal de proteção ao patrimônio histórico. Essa normativa resulta do Plano de Preservação dos Sítios Históricos do Recife - PPSH, do ano de 1979, sob a lei n 13.957. Entre as categorias de sítios sob a regência do Plano de Preservação, o bairro de São José e de Santo Antônio, bairro vizinho intrinsicamente relacionado, classificam-se como Conjuntos Antigos. Segue a caracterização da área em foco:

A superfície protegida dos dois bairros atinge 73,67 hectares e somente é superada pela superfície de proteção da ilha do recife, com 109 hectares. O perímetro de proteção rigorosa supera o dobro da superfície do Plano de gabarito da antiga cidade holandesa. Está configurado por quatro Zonas de Proteção Rigorosa e 11 Zonas de Proteção Ambiental... As Zonas Rigorosas abarcam as construções mais significativas, não necessariamente as construções tombadas pelo Iphan, e, normalmente, agregam o conjunto urbano a elas circundantes, considerando-se seu grau de conservação e integridade artística e formal, levando-se em consideração as transformações ocorridas ao longo do tempo. As Zonas de Proteção Ambiental caracterizam-se pelo conjunto imediatamente continuo às áreas mais destacadas ou delimitadas como Zona Rigorosa. (REYNALDO, 2017, p. 362) 
Diferentemente de planos e instrumentos normativos pretéritos, baseados na proteção de construções tidas como singulares, o PPSH-Recife foi a primeira normativa fundamentalmente protecionista e com clara preocupação contextualizante para a cidade do Recife, segundo Amélia Reynaldo (2017). Ainda de acordo com o citado estudo, o PPSH pautou-se em tendências de cunho exclusivamente protecionistas advindas de encontros internacionais, principalmente o de Amsterdam em 1975, no qual houve uma profunda defesa da importância da incorporação do conjunto urbano no entendimento sobre proteção do patrimônio arquitetônico europeu. Ao ampliar o sentido de proteção da construção singular para o espaço circundante no qual esses edifícios estão inseridos, vislumbrando uma paisagem histórica, temos a ascensão de zonas, manchas, áreas de proteção históricas dentro da cidade do Recife.

A tomada de consciência de que a paisagem em si é potencial objeto de proteção, e não necessariamente como um anexo do edifício singular, tomou corpo a partir dos anos 1990 no nível das organizações internacionais como no Comitê do Patrimônio Mundial da UNESCO. Entretanto, a paisagem já aparecia como preocupação no âmbito da proteção do patrimônio histórico desde a primeira metade do século XX, segundo Rafael Winter Ribeiro (2007, p. 38) "a Carta de Atenas de 1931 já apontava uma preocupação para com aspectos da visibilidade dos monumentos e de sua vizinhança ... a preocupação central estava ligada sobretudo com a ambientação de um determinado bem cultural.”.

No Brasil, o termo paisagem constava no primeiro projeto que visava a proteção dos bens e imóveis de valor nacional, apresentado em 1936, por Mario de Andrade, no ambiente institucional do Serviço do Patrimônio Histórico e Artístico Nacional - SPHAN (REYNALDO, 2017). O interesse na paisagem se confirma através da criação dos Livros do Tombo, quatro ao total, em 1937, sendo um deles o Livro do Tombo Arqueológico, Etnográfico e Paisagístico. Quase 30 anos depois da criação desses Livros, nos anos 1960 e1970, é que veio a ocorrer um aumento de abertura de processos destinados ao mencionado Livro como, também, houve inscrição de conjuntos urbanos cujos processos foram abertos ainda na década de 1940 .

Convém observar que Mário de Andrade - autor do anteprojeto de lei (encomendado pelo Ministro Capanema - 1934/1945) que propõe a criação do Serviço do Patrimônio Artístico Nacional - ao se referir à categoria arte popular, preconizava a preservação de “determinados lugares agenciados definitivamente pela indústria popular, como vilarejos 
lacustres vivos da Amazônia, tal morro do Rio de Janeiro, tal agrupamento de mocambos no Recife, etc." (1980, p.95). O reconhecimento dessas paisagens pobres urbanas como arte, amplia a noção de cultura. Não sem razão Lacerda (2012, p. 48) afirma:

É extraordinário perceber que há, aproximadamente, setenta anos, alguém tivesse a lucidez de perceber que certos agenciamentos de habitações - mesmo populares e muitas vezes precários - conformavam um patrimônio, revestiam-se de características que lhes conferiam o status de bens culturais, ou seja, impregnados de valores. Nesse caso, trata-se de considerar o próprio habitat como um ato cultural por compreender uma totalidade complexa feita de normas, de hábitos, de repertórios, de ações e de representações dos seus habitantes enquanto membro de uma determinada comunidade. (LACERDA, 2012, p. 48)

Esse entendimento de cultura, que inclusive abraça a noção de paisagem, ou viceversa, vem conduzindo obrigatoriamente, a reconhecer as diversas formas de produção do espaço urbano como manifestações culturais, mesmo aquelas formas edificadas pela "indústria popular." ${ }^{3}$ No caso dos becos de São José, trata-se não da construção desses espaços. Afinal, os becos estavam lá, desde o início da sua ocupação quando, após a expulsão dos holandeses, o modelo urbanístico passou a seguir os cânones lusitanos. Trata-se sim das atividades neles desenvolvidas, ou melhor, da forma de ocupação e de apropriação desses espaços estreitos ocupados por barracas, amontoadas de roupas, de utensílios, de ervas..., abarrotadas de gente. Portanto, nesse caso, trata-se de considerar o beco - na sua materialidade e na sua imaterialidade - como um ato cultural, com conteúdo espacial ao mesmo tempo arquitetônico e geográfico, no sentido apontado por Lacerda e Leitão (2016). Ora, se eles são reconhecidos pelo seu valor cultural, constituem em si, bens patrimoniais, devendo ser conservados, isto é, requalificados, quando necessário, não permitindo jamais o seu desaparecimento. Uma análise geográfica das vielas, isto é, partindo de sua interpretação crítica no contexto urbano atual (exterior), permite refletir sobre sua ordenação prospectiva (interior), enquanto composição de um lugar onde vivem pessoas, própria do fazer arquitetônico.

Para além deste debate, importa anotar que o IPHAN define como bens culturais de natureza imaterial "àquelas práticas e domínios da vida social que se manifestam em saberes,

\footnotetext{
${ }^{3}$ Importa registrar que tal entendimento foi absorvido, muitos anos depois, pela Carta de Veneza, de 1964, que elevava à categoria de monumento conjuntos urbanos modestos.
} 
ofícios e modos de fazer; celebrações; formas de expressão cênicas, plásticas, musicais ou lúdicas; e nos lugares (como mercados, feiras e santuários que abrigam práticas culturais coletivas)" (IPHAN, 2017). Ademais, a Constituição de 1988, por meio dos seus artigos 215 e 216, amplia a noção de patrimônio cultural, ao reconhecer a existência de bens culturais de natureza material e imaterial. Não sem razão, esse Instituto, por meio do Decreto $n^{0}$. 3.551 , de 4 de agosto de 2000, instituiu o Registro de Bens Culturais de Natureza Imaterial e criou o Programa Nacional do Patrimônio Imaterial (PNPI), além de consolidar o Inventário Nacional de Referências Culturais (INCR).

Retomando o assunto do aumento de inscrições nos Livros dos Tombos, não é à toa o seu crescimento exponencial. Este teve por base a atribuição de valor não exclusiva "por critérios estéticos e de monumentalidade dos bens, mas incluindo também valores históricos e culturais, todos reunidos através da categoria de paisagem. " (RIBEIRO, 2007, p. 91). Sendo assim, toda a paisagem é cultural, porquanto "área composta por associação distintas de formas ao mesmo tempo físicas e culturais (CORRÊA \& ROSENDAHL, 1998, p. 23). Ao ser cultural, ela é obrigatoriamente histórica. Não se deve olvidar que, se o passado é culturalmente construído, o valor histórico, por si só, está impregnado de valor cultural na medida em que reforça a identidade social.

Desde então, o interesse pela paisagem no âmbito do patrimônio cultural e das políticas urbanas em geral tem crescido no Brasil e no mundo. As construções de novos instrumentos, como a tipologia de paisagem cultural da UNESCO e a Chancela de Paisagem Cultural do IPHAN, são eloquentes quanto ao fenômeno de revalorização dos espaços originários das cidades. Para a UNESCO (2005), conforme o Memorando de Viena, paisagens urbanas históricas "coadunam-se com expressões sociais do presente e do passado, apresentando dinâmicas singulares e vinculadas aos seus sítios geográficos e à sua localização. Compõem-se de elementos definidores que incluem padrões de uso do solo, organização espacial, relações visuais, topografia e vegetação, além de todos os elementos da infraestrutura técnica, como objetos de pequena escala e detalhes de construção". O Memorando de Viena propugna também que a noção de paisagem urbana histórica vá além dos tradicionais centros históricos ou perímetros tombados, para incluir um contexto territorial e paisagístico mais amplo.

Além disso, observam-se contemporaneamente movimentos de contestações que fundamentam seus questionamentos não apenas no direito à cidade, mas também à paisagem. Assim, a paisagem como categoria para a gestão urbana tem sua valorização e proteção 
convertidas em temas importantes para a organização espacial e produção de discursos sobre a cidade e a prática da cidadania (RIBEIRO, 2015).

Lúcia Veras - em seu livro Paisagem-postal: a imagem e a palavra na compreensão de um Recife urbano (2017) - analisa o cerne da questão: a compreensão da paisagem como caminho para se pensar e realizar proposições para a cidade. Tendo como empiria os bairros de São José e de Santo Antônio, essa autora identifica dois tipos de olhares paisagísticos, ou melhor, dois recortes territoriais, ou ainda, dois enquadramentos: o sky line (a linha do horizonte) e land line (a linha do chão). O land line é a paisagem dos frequentadores desses bairros, dos lojistas, dos vendedores, dos camelôs, dos mendigos. Para usar as palavras da autora, é a paisagem do miudinho, do burburinho do cotidiano.

Assim, analisar os becos no contexto de São José, nos coloca na linha do chão e, também, diante de alguns desafios: primeiro, observar o lugar das referidas ruelas na dinâmica de pequena escala no contexto de interior da área sob proteção, em seguida, considera-los no contexto territorial e paisagístico maior em que o bairro se insere e, por fim, balizar o exercício de olhar de dentro e de fora a partir da concepção de que o "regime escópico" que orienta as visualidades e imagens icônicas do perímetro tombado do bairro de São José tende a invisibilizar os becos.

\section{O LUGAR DO (IN) VISÍVEL NA DINÂMICA DE ÁREAS PROTEGIDAS}

Se consideramos aqui que o regime escópico é uma categoria heurística através da qual as maneiras de se levar em conta os becos no centro tombado do Recife podem ser interpretados, sugerimos também que a espacialidade desses lugares seja tomada como um condicionante incontornável do olhar.

Grosso modo, regime escópico refere-se à experiência intersubjetiva de como olhar ou examinar algo. Segundo o Keywords Glossary da Universidade de Chicago (2004) escopo vem do latim "scopium" e quer dizer algo visado, que se deseja atingir. Ainda segundo o glossário, outra maneira de se entender a noção foi introduzida pela primeira vez por Christian Metz (1982), crítico de cinema francês, que pretendia opor-se à ideia de uma visão neutra e universal.

Assim, Metz trouxe a proposta de que regime escópico significaria que existem formas específicas de ver que são manifestações da cultura, ou seja, o ato de ver não seria natural, mas construído culturalmente. Seria uma experiência abrangente do olhar, tal como 
promulgada por uma cultura como um todo. Segundo Campbell e Power (2010) o historiador e estudioso da cultura visual Martin Jay desenvolveu posteriormente a ideia de regimes escópicos a partir do trabalho de Metz. "Em termos de visualidade, Jay argumentou que o perspectivismo cartesiano - que combinava noções renascentistas de perspectiva com ideias cartesianas de racionalidade subjetiva - produziu um regime escópico dominante, senão hegemônico, em que o olho singular do observador controlaria tudo de modo frio e de antemão, consoante uma visão científica de mundo" (CAMPBELL; POWER, 2010, p.2-3)

Enfim, repertório de práticas perspectivas, incorporadas em uma economia visual global, os regimes do olhar estabelecem uma dada relação entre observador e observado. Podem ser tão poderosos nas ações que provocam, ao longo do tempo, um enquadramento forçado, como imaginar os becos como espaços perigosos e repleto de marginais, por exemplo. Mas, ainda como dizem Campbell e Power (2010), são quadros que produzem um campo de realidade perceptível e que podem ser, acima de tudo, significativos para estabelecer as condições de uma resposta ética aos eventos e problemas colocados por sua própria existência.

Por essa perspectiva, os becos, por sua espacialidade e sociabilidade específica, produzem um modo de encarar a "vida" na cidade que deve ser considerada patrimônio também, pois representa tipos de trocas, de conversas, de posturas e de jeitos de ser daquele bairro e até do Recife em seu conjunto. Mesmo que não sejam expostos e expressivos como os grandes e formosos monumentos (igrejas barrocas, mercado e casarios do século XIX, pátios, etc.) fazem parte dessa paisagem cultural. São pouco expressivos imageticamente, mas muito simbólicos de nossos desejos, memórias, modos e até medos. Como disse Fengqi Qian (2008, p.4) a respeito de Pequim, becos estreitos que ligam vias principais "servem não apenas como corredores de trânsito, mas também como locais de encontro público.”.

Em Recife, encontros similares acontecem, mais resguardados da vista dos demais frequentadores de espaços públicos abertos. Se os becos não saem bem na foto, tampouco saem de nossas cabeças, se por lá nos aventurarmos em busca de mercadorias, pessoas ou afazeres. Essas humildes e discretas passagens são como que bens culturais que remetem a uma situação de memória (memória viva): de ir às compras, ir "à cidade" (metonímia de centro comercial do Recife), muitas vezes evocando flashes de primeiras recordações, lembranças de estar na rua com pais ou familiares, em busca de produtos e artífices 
especializados ${ }^{4}$. São parte de um fio da meada perdido por grande parte das pessoas, que hoje só conhecem gôndolas de supermercado ou aleias de shoppings, simulacros pasteurizados da algazarra das vielas comerciais.

Entretanto, beco não pode ser entendido em si e per se: ele faz parte do conjunto que traz na origem fragmentos do urbanismo português, mas que se tornou decididamente uma característica luso-brasileira, admitindo influências das mais diversas, desde aquelas dos mercados sírio-libaneses ou marroquinos até as "supernovas" tinturas das lojas asiáticas.

Aliás, becos, mercado, pátios, cais e feiras são parte desta Recife portuária, uma grande feira entre o rio e o mar, aquilo que o 'vuco-vuco' de hoje ainda evoca, incluindo o grande movimento de usuários de transporte coletivo do "cais de Santa Rita" ou na rua "da praia". O beco do Sirigado evoca o nome de um peixe (também conhecido por badejo): uma geografia popular em que tudo cheira a maré. Outra vez recorrendo à analogia sino-brasileira, os nomes de alguns becos em Pequim, como beco da seda e beco da porcelana, são altamente indicativos da função passada do bairro em que se encontram (QIAN, 2008, p.4).

Qual, portanto, o convite que fazemos aos leitores: que passem a olhar as áreas protegidas nas cidades históricas do Brasil também através da janela dos becos - e não somente a partir de grandes panoramas dos conjuntos históricos. No caso, São José e santo Antônio, a partir das suas vielas, adquire uma profundidade ímpar como ambiente de encontros, saberes ou comportamentos, deixando à superficialidade das paisagens postais o posto de primeiro contato, primeira impressão que nos provoca a penetrar, através de inusitadas aberturas, no genius loci.

\section{NOTAS FINAIS}

O que o caso dos becos recifenses nos ensina? Que na esteira do Patrimônio Histórico cabe incorporar os espaços cotidianos e sua sociabilidade histórica que esses propiciam, mesmo na modernidade e na mudança. A vida de lugares tombados depende da vivacidade/vitalidade dos espaços - e os becos, lugares de trocas e atalhos, são funcionalmente úteis e muito eficazes em atrair pessoas e ações ao longo do ano, e não só em efemérides turísticas.

\footnotetext{
${ }^{4}$ Em trabalho de campo da disciplina Tópicos Especiais em Geografia Cultural realizado com turma de pósgraduação (PPGEO/UFPE) em dezembro de 2016, vários dos alunos reportaram lembranças de infância ao percorrerem os becos do Sirigado e do Marroquim, em São José. Como disse o doutorando Paulo César de Oliveira "é fácil de recordar o aroma cítrico das frutas tropicais, misturado pelo vento úmido com outros odores como de cigarro, dinheiro sujo, suor e poeira". 
Se assim é, defende-se aqui a institucionalização das atividades dos becos do Bairro de São José enquanto manifestações culturais, porquanto se conformam como uma peculiar forma de ocupação, de apropriação do espaço urbano. A sua materialidade, como visto, encontra-se protegida. Afinal, os becos desse bairro, junto com o mercado, as igrejas, os pátios e o sobrados definiram a sua paisagem secular cujas principais características ainda sobrevivem nos dias atuais. Esse conjunto integra áreas protegidas pela normativa urbanística da Cidade do Recife. Todavia a atividades nele instaladas, o burburinho por elas gerado precisa de proteção especial para que não desapareça. A materialidade desses espaços passou a ser agenciada (organizada) e apropriada de forma peculiar (imaterial), por sujeitos sociais que ali se instalaram, que por ali transitam, sujeitos despojados, rodeados de mercadorias populares. Somente com a institucionalização desse conjunto - material e ao mesmo tempo imaterial, os becos não mais seriam considerados de forma pejorativa.

Beco é lugar de encontro público entre o antigo e o contemporâneo, "sem as muletas da musealização" como disse Frederico Pernambucano de Mello sobre a Feira de Caruaru (in MEDEIROS, 2006, p.78); portanto não se pode pretender congelar/reformar os becos à imagem e semelhança do passado, mas ressaltar o quanto há de positivo em sua dinâmica própria no contexto do espaço sob proteção das leis municipais do patrimônio histórico.

Neste sentido, a vocação dos becos no conjunto tombado de São José não deve (nem poderia) ser aquela do monumento ou da simples forma arquitetônica, por mais pitoresca que seja. Ao contrário, a grande potencialidade do beco é fazer ecoar a febre de passantes, pedintes, pedestres, trabalhadores e consumidores que se aproximam, se ouvem se tocam e induzem a um tipo de interação social somente possível pelo "constrangimento consentido" de sua reduzida largura e singular verticalidade de luz. É um traçado urbano histórico somado a dinâmica funcional e sentimental que contextualiza o patrimônio legalizado.

Os becos aqui estudados, por fim, são uma reminiscência do fervor comercial das ruas de São José e Santo Antônio, que mesmo após mudanças de hábitos, transformações na centralidade urbana, no perfil demográfico e nos modos de consumo da população como um todo conseguiu manter certos nichos (beco dos alicates, beco onde se vende lingerie...) e muito charme: a aura do mistério de penetrar nas frestas da cidade, ver de perto seus personagens e arestas, escutando seus diferentes sotaques e apelos. 


\section{REFERÊNCIAS BIBLIOGRÁFICAS}

ANDRADE, Mário de. Anteprojeto de Lei. In MEC.SPHAN, Pró-memória. Proteção e revitalização do patrimônio cultural no Brasil: uma trajetória. Brasília, 1980.

CAMPBELL, David; POWER, Marcus. The Scopic Regime of Africa. In: F. MacDonald et al. Observant States: Geopolitics and Visual Culture. London and New York: I. B. Tauris, 2010, p. 167-198.

CORRÊA, R. L.; ROSENDAHL, Z. Paisagem, tempo e cultura. Rio de Janeiro: EdUERJ, 1998.

GASPAR, Lúcia. Mercado de São José. Fundação Joaquim Nabuco: Recife. Disponível em: $<$ http://basilio.fundaj.gov.br/pesquisaescolar/>. Acesso em: 21 jan. 2017.

HALLEY, Bruno Maia. Arruando pelo beco: um nome do passado evocado no afeto e no desamor da gente da cidade. Revista de Geografia, PPGEO, v. 2, no 1 (2012).

INSTITUTO DO PATRIMÔNIO HISTÓRICO E ARTÍSTICO NACIONAL. Patrimônio imaterial. In: http://portal.iphan.gov.br/pagina/detalhes/234. Acesso em: 30 de agosto de 2017.

LACERDA, Norma. Os valores dos bens patrimoniais. In: LACERDA, Norma \& ZANCHETI, Sílvio. Plano de gestão da conservação urbana: conceitos e métodos. Olinda, Ceci, 2012.

; LEITÃO, Lúcia. O espaço na geografia e o espaço da arquitetura: reflexões epistemológicas. Caderno Metropolitano, São Paulo, vol. 18, nº 37, p. 803-822, set/dez 2016. Disponível em: http://dx.doi.org/10.1590/2236-9996.2016-3709, acessado em 01 de setembro de 2017.

LOUREIRO, Cláudia; AMORIM, Luiz. Vestindo a pele do cordeiro: requalificação versus gentrificação no Recife. Urbana. Revista Eletrônica do Centro Interdisciplinar de Estudos da cidade, v.1, 2006. Disponível em: http:/www.ifch.unicamp.br/ciec/revista/. Acesso em 30 de agosto de 2017.

MACIEL, C. A. A.. A Geografia política da paisagem: imagens, narrativas e sensibilidades culturais em disputa no espaço público recifense. In: MACIEL, C.A.A; GONÇALVES, C.U.; PEREIRA, M.C.B. (Org.). Abordagens Geográficas do Urbano e do Agrário. $1^{\mathrm{a}}$ ed. RECIFE: Editora da UFPE, 2012, v.1, p. 26-41. 
MEDEIROS, B. F. Dossiê Feira de Caruaru. Inventário Nacional de Referência Cultural. Iphan, 2006. Disponível em: http://portal.iphan.gov.br/pagina/detalhes/61 acesso em 06-062017.

PESAVENTO, Sandra Jatahy. "Era uma vez o beco: origens de um mau lugar”. In: Palavras da Cidade. Rio Grande do Sul: Ed. da Universidade, 2001. p. 97 a 120.

QIAN, Fengqi. Protecting the Spirit of Hutong. A Case Study of Nanchizi Precinct, Beijing. In: 16th Scientific Symposium of ICOMOS. Québec, 2008. Disponível em: http://www.icomos.org/quebec2008/cd/toindex/77_pdf/77-BCkP-152.pdf . Acesso em 11 de junho de 2017.

RIBEIRO, Rafael Winter. Paisagem Cultural e Patrimônio. Rio de Janeiro: IPHAN/COPEDOC, 2007.

. Política da Paisagem Urbana: representações, ações e contestações no Rio de Janeiro e Recife. Projeto de pesquisa: Rio de Janeiro, 2015.

THE UNIVERSITY OF CHICAGO. Theories of Media : Keywords Glossary : scopic, vocative Disponível em: http://csmt.uchicago.edu/glossary2004/scopicvocative.htm . Acesso em 31 de maio de 2017. (Tradução livre: Caio Maciel).

UNESCO World Heritage Centre. The Vienna Memorandum on 'World Heritage and contemporary architecture - managing the historic urban landscape'. 2005, Disponível em: http://whc.unesco.org/archive/2005/whc05-15ga-inf7e.pdf, acessado em 11 de junho de 2017.

VASCONCELOS, Priscila Batista e MACIEL, Caio Augusto Amorim. No mais entranhado da cidade: imagens e espacialidades dos becos no centro histórico do Recife. Revista Espaço e Cultura, n. 39 (2016), Janeiro-Junho.

VERAS, L. M. DE S. C. Paisagem-postal: a imagem e a palavra na compreensão de um Recife urbano. Rio de Janeiro: Letra Capital, 2017. 